\title{
Aristotle on the Heterogeneity of Pleasure
}

Matthew Strohl

Aristotle famously claims that pleasures differ from one another in kind in accordance with differences in kind among the activities they arise in connection with-call this the Covariance Thesis. This aspect of Aristotle's theory of pleasure contrasts sharply with the prevalent conception of pleasure as a phenomenally characterized type of feeling. If it is true, 'pleasure' must be nearly as diverse a concept as 'activity'. It seems quite clear that to maintain the Covariance Thesis, Aristotle must deny that pleasure is a phenomenally characterized type of feeling, as it is hard to imagine that the phenomenal character of the feelings associated with reading a $19^{\text {th }}$ century Russian novel on the one hand and eating a cupcake on the other could differ in a way that reflects the difference in kind between these two activities. The former activity is primarily cognitive and the latter is primarily sensory, and it does not seem plausible that this fundamental difference in kind could be reflected by phenomenal differences between two feelings.

I claim that Aristotle denies that pleasure is any type of feeling that arises in connection with our activities and instead takes pleasure to be an aspect of the activities themselves. ${ }^{1}$ In particular, he takes pleasure to be the character that activities gain when there is a certain type of fit between the condition of the capacity being activated and the object that it is active in relation to. The paradigm case is the case where the capacity is in the best possible condition and the object is the best or finest (most kalon) of the range of objects that the capacity engages with. In

\footnotetext{
${ }^{1}$ Matthew Strohl, "Pleasure as Perfection: Nicomachean Ethics X.4-5," Oxford Studies in Ancient Philosophy 41 (2011): 257-287.
} 
such cases, there is a fit between capacity and object in the sense that the capacity is in a condition to be activated in a manner that most fully realizes its nature as the capacity that it is and the object is such as to enable the full engagement of the capacity in such a condition. Such activities are considered "perfect" in virtue of this fit and pleasure is identified with their very perfection.

I take it that Aristotle's understanding of pleasure as the perfection of perfect activity grounds his assertion of the Covariance Thesis. That is, he thinks that the relationship between pleasure and the activity it arises in connection with entails their covariance in kind. In this essay, I will defend this claim by developing an interpretation of the series of arguments that Aristotle gives for the Covariance Thesis in Nicomachean Ethics 10.5. In section 1, I explain Aristotle's account of pleasure as the perfection of perfect activity in greater detail. In section 2, I discuss Aristotle's first argument for the Covariance Thesis, according to which it follows from his account of pleasure as an aspect of perfect activity. When activities vary in kind, so too does this aspect. Because of pleasure's nature as an aspect of activity that varies in kind along with it, pleasure must be phenomenally heterogeneous in much the same manner as mental activity is. In section 3, I discuss his second argument, according to which the Covariance Thesis follows from the fact that the proper pleasure "increases" activity. Pleasure, in virtue of being the perfection of a perfect activity, bears a special relation to this activity such that it amplifies it in certain respects. This argument indicates that while Aristotle denies that pleasure is defined phenomenologically, he does think that pleasures have a phenomenal structure in common. In section 4, I discuss Aristotle's third argument, according to which the Covariance Thesis follows from the fact that an alien pleasure destroys activity. This argument sheds further light on the second argument and brings out additional details concerning the phenomenal structure of 
pleasure and the causal relationships between pleasures arising in connection with distinct activities. Finally, in section 5 I consider the difficult question of whether Aristotle's acceptance of the Covariance Theisis entails that pleasures differing in kind cannot be compared in pleasantness. I point to strong textual evidence that he thinks that pleasures differing in kind can indeed be compared in pleasantness, and suggest how his account might allow for this.

\section{Section 1: Pleasure and perfect activity}

Aristotle's most famous remark on the nature of pleasure is the notorious simile of the bloom:

Pleasure perfects [ $\tau \varepsilon \lambda \varepsilon \delta \tilde{I}]$ the activity — not, however, as the state does, by being

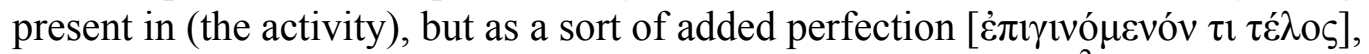
like the bloom on those in the prime of youth. $(N E 1174 \mathrm{~b} 31-33)^{2}$

Many commentators have found this passage to be unclear or confused. ${ }^{3}$ It may seem as though Aristotle is struggling to express an important idea with a vague simile rather than spelling it out clearly because he does not in fact have a coherent view about what pleasure itself is. He is committed on the one hand to denying that pleasure is identical to pleasant activity, and on the other hand to denying that pleasure is separate from pleasant activity. ${ }^{4}$ Elizabeth Anscombe

\footnotetext{
2 Translations from the $N E$ are based on T.H. Irwin, (trans. and comm.), Aristotle: Nicomachean Ethics (Indianapolis: Hacket, 1999), and have sometimes been modified.

${ }^{3}$ W.F.R. Hardie, Aristotle's Ethical Theory (Oxford: Oxford University Press, 1980): 314; C.C.W. Taylor, "Pleasure: Aristotle's Response to Plato," in Plato and Aristotle's Ethics, ed. R. Heinaman (Aldershot: Ashgate, 2003): 19-20; David Bostock, "Pleasure and Activity in Aristotle's Ethics," Phronesis 32 (1988): 251. ${ }^{4} N E$ 1175b30-33.
} 
famously remarked that he was reduced to "sheer babble" by the lack of options he is left with due to these two commitments. ${ }^{5}$

I claim, on the contrary, that Aristotle is in fact stating an intelligible view reasonably clearly in this passage. To understand his meaning, it is necessary to interpret the simile in close connection with the preceding text. Aristotle has already established a connection between an activity's pleasantness and its perfection:

Every perceptual capacity is active in relation to its perceptible object, and perfectly active when it is in good condition in relation to the finest of its perceptual objects. For this above all seems to be the character of perfect activity, and it doesn't matter if we ascribe it to the capacity or to the subject that has it. Hence for each capacity the best activity is the activity of the subject in the best condition in relation to the best object of the capacity. This activity will be the most perfect and the most pleasant. (NE 1174b14-20)

He tells us clearly in this passage that an activity is perfect when the capacity being activated is in a good condition in relation to a fine object. The idea, I take it, is that when the capacity being activated is in a good condition it becomes possible to more fully utilize the capacity in question with respect to its natural end. The natural end of our capacity for sight is seeing, and when the capacity is in a good condition it is possible to more fully realize this end. It is not sufficient for a capacity to be in a good condition for it to fully realize its natural end, however, since it also needs an object that is apt fully to make use of this good condition. A capacity for seeing in the best possible condition would not be perfectly activated if its object were something ugly or mundane. ${ }^{6}$ In order for the resultant activity to be perfect, a capacity in a good condition

\footnotetext{
${ }^{5}$ G.E.M. Anscombe, "Modern Moral Philosophy," in The Collected Philosophical Papers of G.E.M. Anscombe, vol. 3, Ethics, Religion, and Politics. (Oxford: Basil Blackwell; Minneapolis: University of Minnesota Press, 1981): 27.

${ }^{6}$ To fully activate a capacity, it is not sufficient to merely utilize it completely (a thoroughly ugly object could perhaps do this). The full activation of a capacity entails fully realizing its nature as
} 
must be active in relation to a fine object, one that is apt in virtue of its fineness to fully utilize the good condition that the capacity is in. ${ }^{7}$ A capacity in a good condition is, as it were, more capacious, and thereby requires a more demanding object for full activation.

The point of the simile of the bloom is to express the idea that pleasure is the very perfection of a perfect activity. When the capacity being activated is in a good condition and is active in relation to a fine object the resultant activity is thereby perfected. Aristotle states in the

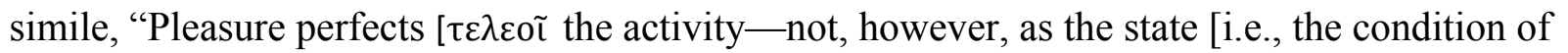
the capacity being activated] does, by being present in (the activity), but as a sort of added

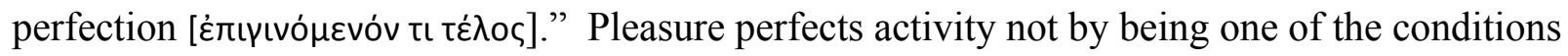
that bring about the activity's perfection, but rather by being the very perfection that the activity attains when these conditions are met. An activity of seeing is not necessarily pleasant, but rather is pleasant when the relevant perfecting conditions are in place. When the activity is perfected, pleasure is the perfect character that it has in virtue of the joint contribution of the good condition of the capacity being activated and the fineness of the object that it is active in relation to. It is the aspect of the character of a perfect activity that distinguishes it from an activity where the conditions required for perfection are not met. "The bloom on those in the prime of youth," is another example of an added perfection. A young person has the bloom when their sexual attractiveness is perfected in virtue of the set of features that come along with

the capacity that it is and as a part of human nature more broadly. This generates normative constraints on the condition that the capacity must be in and the character of the object that it must be active in relation to. See section 1 of Strohl, "Pleasure as Perfection" for a fuller explanation.

${ }^{7}$ I give an account of why fineness is required for the full activation of a capacity in a good condition in Strohl, "Pleasure as Perfection" at 263-5. 
being at the prime of youth. These features bring about the perfection of their sexual

attractiveness, whereas the bloom is identified with this perfection.

One may worry that this account of pleasure is too narrow to accommodate a vast range of cases that we ordinarily consider to be pleasant. I can report with great confidence that I have taken pleasure in many objects that were not at all fine on occasions when my faculties were not in a good condition. Sometimes, for instance, I crave a cheap diner breakfast. When this craving strikes, I would not enjoy a nice breakfast at a fancy bistro as much as I would a plate of cheap diner food. Is Aristotle committed to denying that I experience pleasure on such occasions? The answer is surely that he is not. ${ }^{8}$ At $N E$ 1126a10-29, Aristotle clearly states that people who are in a deficient condition also take pleasure, but they take it in inferior objects that match their condition. I take it that the idea is that in these deficient cases, the relation between the condition of the subject's faculties and the object that they are active in relation to is analogous to the relation between faculties in a good condition and a fine object. Aristotle is happy to call such derivative cases instances of 'perfection', just as we speak of someone being a 'perfect thief' even though being a thief is not a good thing. ${ }^{9}$ What unites all cases where an activity is pleasant is that there is a fit between the condition of the subject's faculties and the object they are active in relation to. When one's faculties are in a good condition, they fit with a fine object; when they are in a deficient condition, they fit with an inferior object. ${ }^{10} \mathrm{He}$ calls cases where the fit is between a good condition and a fine object unqualified pleasures and derivative cases qualified

\footnotetext{
${ }^{8}$ Here I disagree strongly with Gerd Van Riel, Pleasure and the Good Life. [Leiden: Brill, 2000], 77.

${ }^{9}$ Cf., Metaph. $\Delta$ 16, 1021b17-19

${ }^{10}$ This is not to say that a stoned teenager could not take pleasure in Mahler's $9^{\text {th }}$ Symphony, but rather that in such a case the teenager would not be engaging with the same object as the practiced music lover, because the piece would not be apprehended in its full fineness.
} 
pleasures because in derivative cases the pleasantness of the activity depends on the subject being in a deficient condition and so we can only say that the activity is pleasant for a subject in a given condition, whereas in unqualified cases the activity is pleasant for human beings when they are in a condition that fulfills their essential nature as such and so no qualification is needed and the activity can simply be said to be pleasant.

\section{Section 2: The significance of Aristotle's conception of pleasure as an aspect of activity}

After presenting his theory of pleasure in $N E$ 10.4, Aristotle turns in 10.5 to give a series of arguments for the Covariance Thesis. These arguments help considerably in clarifying his theory of pleasure and also what he takes its significance to be. They are also our best evidence about Aristotle's understanding of the way that pleasure is experienced. The overall picture of the phenomenology of pleasure that emerges from these arguments is that there are no phenomenal elements that all pleasant experiences have in common, but that all pleasant experiences do share a certain phenomenal structure. In this section, I will be concerned with the first argument, according to which the Covariance Thesis follows from the nature of pleasure as the perfection of perfect activity. Aristotle's basic reasons for denying that there is a unified phenomenology of pleasure emerge from this argument.

Aristotle writes:

Hence pleasures also seem to differ in kind. For we suppose that things that differ in kind are perfected by different things. This is how it appears, both with natural things and artifacts, such as animals, trees, a painting, a statue, a house, or an implement. Similarly activities that differ in kind are perfected by things that differ in kind. Activities of thought differ from activities of perception in kind, and these activities of perception 
differ from each other in kind; and so the pleasures that perfect these activities also differ in kind. (NE 1175a21-28)

The word 'hence' [ö $\theta \varepsilon v]$ refers back to the claim made in the last sentence of the previous chapter, where Aristotle says that there is no pleasure without activity and that pleasure perfects every activity (which is not to say that every activity is perfect, but rather that every activity, when it is perfected, is perfected by pleasure). This indicates that his argument here hinges on his identification of pleasure with the perfection of a perfect activity. In $N E 10.4$, at $1174 \mathrm{~b} 23$ 26 , he clarified that the way in which pleasure perfects activity is not the same as the way in which the perceptual capacity and perceptual object perfect it, just as health and a doctor are not causes of being healthy in the same way. A doctor is the cause of being healthy in the sense that the doctor brings it about that a patient becomes healthy, but there are other ways of being a cause of being healthy. Health is also the cause of being healthy, not by bringing it about that a patient becomes healthy, but rather by being the condition that the patient acquires when she becomes healthy. The analogy should not be taken to imply that pleasure is in some sense a cause of perfect activity. The point is rather that just as there are several ways of causing something, there are several ways of perfecting something. Pleasure perfects activity, not by bringing it about that it becomes perfect, but rather by being the very perfection that it gains when there is the right kind of fit between object and capacity.

When Aristotle refers in the passage quoted above to the "different things" that perfect things that are different in kind, I take it he is referring not to the things that bring perfection about, but rather to the very perfection that things gain when they are perfected. He makes it very clear in the analogy with health discussed above that pleasure does not perfect activity by bringing it about that an activity becomes perfect, and so the first argument for the Covariance 
Thesis is invalid if he is using the verb 'perfect' in the sense of 'bringing it about that something become perfect'. The correct interpretation of the argument, I take it, is that just as the perfection of one kind of thing is different in kind from the perfection of another kind of thing, so too this is true for activities. The perfection of an activity of thought differs in kind from that of an activity of perception, and the perfection of an activity of hearing differs in kind from the perfection of an activity of seeing. Since pleasure is the perfection of a perfect activity, it follows that pleasures differ from one another in kind. ${ }^{11}$

This argument sheds light on the basis of the Covariance Thesis and also on its significance. Pleasure, for Aristotle, is not something that we experience as a result of performing an activity, as a sort of reward or incentive. Rather, pleasure is identified with an aspect of the activity itself, namely, the perfection that it gains in virtue of the fit between the condition of the subject's capacity and the object it is active in relation to. When activities vary in kind, this aspect varies along with them. The pleasure associated with an activity of seeing differs in kind from the pleasure associated with an activity of smelling in much the same way as the perfection of a well-designed bed differs from the perfection of a particularly effective blender. Beds and blenders are different kinds of things, and the aspects of beds and blenders that contribute to their respective perfection are also different in kind. A bed is perfect (let us suppose) if it is supportive enough to promote good posture while also being soft enough to be comfortable. The perfection of a bed is the character that it has in virtue of these perfecting elements. A blender, on the other hand, is perfect if it can quickly and effectively liquefy anything one might have a reason to liquefy without causing too much noise. The perfection of a blender is the character that it has in virtue of these perfecting elements. The perfecting

${ }^{11}$ This argument is also discussed in section 4 of Strohl, "Pleasure as Perfection." 
elements for a bed are different in kind from the perfecting elements for a blender, and therefore the resultant perfect character for a bed is different in kind from the resultant perfect character of a blender. An activity of seeing is perfect if one's capacity for sight is in a good condition and one engages with a fine visible object, whereas an activity of smelling is perfect if one's capacity for smell is in a good condition and one engages with a fine olfactory object. These sense modalities and the objects they engage with are different in kind, and so it follows that the perfect characters that emerge when there is the right kind of fit between them are different in kind.

The Covariance Thesis, then, is a natural extension of Aristotle's view that pleasure is the perfection of a perfect activity. Every kind of activity has its own kind of perfection, and so the pleasure arising in connection with different kinds of activities will accordingly differ in kind. This understanding of pleasure may seem unduly formal. Pleasure is, after all, something that one experiences. It seems to me that this worry is ultimately unfounded. The Covariance Thesis entails that there will be no particular phenomenal elements that are common to all pleasant experiences, but I will argue in what follows that Aristotle's theory entails a phenomenal structure that all pleasant experiences have in common. The subsequent two arguments that Aristotle gives for the Covariance Thesis in NE 10.5 provide the best basis we have for understanding this phenomenal structure. I will examine them in turn.

\section{Section 3: The "increasing" structure of pleasant experiences}

Aristotle writes:

[That pleasures differ in kind] is also apparent from the way each pleasure is

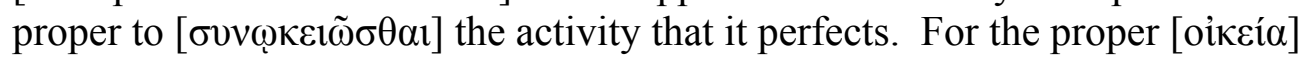


pleasure increases [бvvav́ $\xi \varepsilon 1]$ the activity; for we judge each thing better and more exactly when our activity involves pleasure. If, for instance, we enjoy doing geometry, we become better geometers, and understand each question better; and similarly lovers of music, building, and so on improve at their proper characteristic activity when they enjoy it. Each pleasure increases the activity, and what increases it is proper to it; and since the activities are different in kind, what is proper to them is also different in kind. (NE 1175a29-b1)

The word translated as 'proper', 'oikzia', has the connotations of 'akin to' and 'intimately connected with'. In support of the claim that pleasure is proper to activity in a way that entails their covariance in kind he points to the phenomenon of pleasure "increasing" the activity that it arises in connection with. All else being equal, when one takes pleasure in performing an activity, this leads one to perform it for a longer period of time, more adeptly, with more enthusiasm, etc. If one enjoys thinking about a math problem, one will think about it with greater focus and persistence than if one did not enjoy thinking about it.

Aristotle gives a somewhat elliptical argument for the Covariance Thesis on the basis of this phenomenon: "Each pleasure increases the activity, and what increases it is proper to it; and since the activities are different in kind, what is proper to them is also different in kind." The idea here, I take it, is that the fact that pleasure increases the particular activity that it arises in connection with indicates that it bears a special relation to this activity which he calls 'being proper to it'. This relation entails that the pleasure differs in kind from pleasures that are connected with activities that differ in kind from the activity that it itself is connected with. That is, the relation is such that if $\mathrm{A}$ bears it to $\mathrm{B}$, and $\mathrm{C}$ bears it to $\mathrm{D}$, and $\mathrm{B}$ and $\mathrm{D}$ differ in kind, it follows that $\mathrm{A}$ and $\mathrm{C}$ differ in kind.

I take it that in claiming that pleasure is proper to activity Aristotle is again drawing a corollary of his view that pleasure is the perfection of perfect activity and using this corollary to 
support the Covariance Thesis. The pleasure of listening to music is the perfect character that the activity of listening has in virtue of the interplay between the fineness of the music being listened to and the good condition of one's capacity for listening. Aristotle is claiming that the perfect character of an activity stands in the relation of being proper to the activity itself. This makes sense, as this relation is aptly described as 'intimate' and there is a clear sense in which the perfect character of an activity is 'akin to' the activity itself. Pleasure is the aspect of a perfect activity that differentiates it from a non-perfect activity of the same type. For example, there is a mountain visible from my office window. I see it all the time, and so I don't tend to focus my attention on it enough to appreciate its beauty. It is a fine object, but my usual activity of seeing it is not pleasant, because I am not in a condition to fully engage the relevant faculties when I see it. On some days, however, circumstances collide such that I stop and notice the mountain's beauty and take pleasure in it. I may be in an appreciative mood where I am more inclined to focus my attention on the ruggedness of the landscape around me, and the mountain might be bathed in particularly stunning golden light, so that I suddenly see it perfectly, which is to say that the condition of my faculties and the appearance of the mountain fit together on this occasion. Aristotle identifies the pleasure I experience with the aspect of this experience that differentiates it from my ordinary, non-pleasant experience of seeing the mountain. Pleasure is the character that my activity gains in virtue of the relevant perfecting contributions. It is 'intimately related' to the activity in that it is an aspect of that very activity. It is 'akin' to the activity in that its character derives from the character of the activity. A perfect activity of mountain-seeing give rise to a pleasure that is an aspect of such mountain-seeing, and this pleasure will vary in kind from a pleasure that is an aspect of music-listening or fruit-tasting in a 
way that reflects the difference in kind between activities of seeing on the one hand and listening or tasting on the other.

This story helps us to see why pleasure, understood as the perfection of a perfect activity, 'increases' the activity it arises in connection with. Take a case where I have just had my morning coffee and am feeling prepared to concentrate and in the mood to read. I pick up a good book and quickly start to take pleasure in reading it. The fit between the condition of my capacity for reading and the quality of the book causes me to become increasingly focused as I read and therefore to read more quickly and with greater attention to detail. In the course of reading the book in this focused way I come to a realization about something I had not understood previously, and I begin to think about the book in a deeper way than I was capable of when I began to read. The condition of my capacity for reading is now in a better condition and I begin to enjoy the book more and thus read it with even greater focus, thus putting myself in an even better condition for reading (and so on). In this indirect manner, performing the activity with pleasure improves the condition of my capacity and thereby makes it possible to perform the activity even more pleasantly. ${ }^{12}$ The improvement of my condition involves an increase in my focus on the object, and may involve other changes as well. For instance, when I enjoy reading, my mood may shift so that I am more open to being emotionally affected by what I am reading, which increases my enjoyment and thus further increases my openness to being emotionally affected, and so on. This strikes me as a very plausible way of explaining the phenomena surrounding the pleasure of reading. The same basic story can be told about even,

\footnotetext{
${ }^{12}$ The notion of 'improvement' here is not that the capacity is improved simpliciter but rather that it becomes more apt to fit with the object at hand. When I am taking pleasure in a diner breakfast it does not put me in a condition where I would suddenly prefer fine cuisine, but rather puts me in a condition where I am better able to enjoy the diner breakfast.
} 
e.g., the pleasure of sitting in the sun. The warm feeling of the sun leads us to continue to sit in the sun and to focus on the pleasant sensation of the sun's warmth more attentively.

Aristotle's argument, then, is that the fact that pleasure increases activity in this manner reveals that it is 'proper to' activity so as to entail the Covariance Thesis. In order for the pleasure of reading to put one in a better condition for reading and not for, e.g., fruit-tasting, it must bear a particular relation to one's activity of reading that it does not bear to other activities. It must be the kind of thing that puts one in a better condition for reading in particular, whereas the pleasure of fruit-tasting must be the kind of thing that puts one in a better condition for fruittasting. The two pleasures are therefore different in kind. Aristotle develops this argument further in his third argument for the Covariance Thesis, which I turn to in the section 4 below, by considering what happens when we engage in two activities at once

As I have stated, Aristotle does not think that there is a general phenomenal characterization of all pleasure, since the phenomenal character of any given kind of pleasure will be specific to the activity it arises in connection with. We can now see that he does think that there is structural similarity between the phenomenal characters of all pleasures. Every pleasant experience has the structural feature of increasing (in the sense that has been discussed) due to its pleasant character. This means that ceteris paribus all pleasant experiences have the structure of the subject's focus on the object of experience increasing (and perhaps the subject's condition for engaging with it improving in other ways) and thereby leading the subject to continue to perform the activity and to do with increasing perfection and thus increasing pleasure. This will eventually reach a limit where either the subject has exhausted the object such that it is no longer apt to fully engage the relevant faculties (e.g., I look at a painting with 
increasing focus until I stop noticing anything new and thus my pleasure wanes and so does my focus) or other aspects of the subject's condition interfere (e.g., I study Aristotle with increasing pleasure and focus until I become tired for physiological reasons and my faculties are no longer in a good condition for studying Aristotle and thus my pleasure and focus wane). The way this process of "increasing" proceeds will differ for different kinds of activities, and so it does not entail any particular phenomenal character, but it does entail a structure that the phenomenal character of any pleasant experience will have.

\section{Section 4: Interrelations between pleasures}

Aristotle's third argument for the Covariance Thesis is closely related to the second:

This is even more apparent from the way some activities are impeded by pleasures from others. For lovers of flutes, for instance, cannot pay attention to a conversation if they catch the sound of someone playing the flute, because they enjoy flute playing more than their present activity; and so the pleasure proper to flute playing destroys the activity of conversation. The same is true in other cases also, whenever we are engaged in two activities at once. For the more pleasant activity pushes out the other one, all the more if it is much more pleasant, so that we no longer even engage in the other activity. Hence if we are enjoying one thing intensely, we do not do another very much. It is when we are only mildly pleased that we do something else; for instance, people who eat nuts in theaters do this most when the actors are bad. Since, then, the proper pleasure makes an activity more exact, longer, and better, whereas an alien pleasure damages it, clearly the two pleasures differ widely. For an alien pleasure does virtually what a proper pain does. The proper pain destroys activity, so that if, for instance, writing or rational calculation has no pleasure and is in fact painful for us, we do not write or calculate, since the action is painful. Hence the proper pleasures and pains have contrary effects on an activity; and the proper ones are those that arise

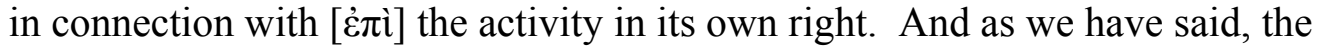
effect of alien pleasures is similar to the effect of pain, since they ruin the activity, though not in the same way as pain. (NE 1175b1-24) 
This is not an entirely new line of argument. It is meant to support the claim that pleasures are proper to the activities they are connected with so as to entail their covariance in kind. Aristotle points to a case where a lover of flute music is engaged in a conversation, but then hears flute music. As she begins to take pleasure in listening to the music, this pleasure increases her activity of listening so that she starts focusing on it more and more intensely. Meanwhile, she is increasingly distracted from the conversation, to the point where her capacity for conversing comes to be in an outright bad condition and she stops taking pleasure in connection with the conversation. Eventually, she stops participating in the conversation all together. ${ }^{13}$ Aristotle's point is that there must be something about the character of the pleasure she takes in listening to flute music that increases the activity of listening but impedes the activity of conversing. Both activities are going on at the same time, and at least at the beginning she experiences pleasure in connection with both. If the pleasures connected with the two activities were the same in kind (as would be the case if, e.g., pleasure were a single feeling), there would be no explanation as to why the pleasure connected with the activity of listening increases that activity but impedes the activity of conversing. The pleasure of listening must be the kind of thing that increases the

${ }^{13}$ Aristotle says in the passage under discussion that an alien pleasure does virtually what a proper pain does. He does not give an account of pain in $N E$ 10.1-5, but one might reasonably infer that just as pleasure is the character an activity has when there is a good fit between capacity and object, pain is the character an activity has when there is a poor fit between capacity and object. Take, for instance, someone has been working on a philosophy article for twelve hours and decides to stop and rest. The person is mentally exhausted, and so if she is later compelled to think about a philosophical problem to answer an email from a student, she will have difficulty focusing and her activity of thinking about the problem will be impeded in various ways. The impeded condition of her activity of thinking, on the suggestion being considered, counts as pain. The pain the person experiences will cause her to do a progressively worse job thinking about the problem and may lead her to abandon the task all together and leave the email for the next morning; it will do virtually the same thing an alien pleasure has been seen to do. 
activity of listening but impedes the activity of conversing, and so must be different in kind from the pleasure of conversing, which is the kind of thing that increases the activity of conversing.

This case supports the claim that pleasures are proper to the activities they arise in connection with because it reveals that pleasures stand in very different causal relationships with these activities than they do with other activities that the subject is engaging in at the same time. The pleasure of listening to flute music increases the activity of listening to flute music while destroying the activity of conversation. If the pleasure attending the two activities were the same, then there would be no reason that the pleasure of music-listening would not increase the activity of conversation as well as the activity of music-listening. The fact that it increases the one activity while destroying the other indicates that it is proper to the activity it arises in connection with and different in kind from the pleasure associated with the other activity.

Aristotle may seem to have neglected an alternative explanation of this phenomenon. If one thinks that pleasure is a single type of feeling, one might think that instances of this feeling bear certain causal relations exclusively to the activities they are connected with. On this view, if I am enjoying listening to flute music and conversing at the same time, I experience two instances of the same type of feeling that have distinct sets of causal relations. The pleasure connected with listening to flute music may be related to the activity of listening in such a way that it increases it, but be related to the activity of conversation in such a way that it impedes it. It does not seem right, however, to think that when I take pleasure in two different activities simultaneously I experience two instances of the same type of feeling. It is not even clear what it would be to experience two instances of the same type of feeling at the same time. For instance, if I am nervous both about giving a talk and about getting the results of a blood test, I simply feel 
nervous. It seems bizarre to say that I feel two instances of nervousness at once. The cognitive aspect of my nervousness might be twofold, but not the affective aspect.

Aristotle's empirical observation that the pleasure associated with a given activity impedes other activities may seem false, especially in so far as we think that some pleasant activities synergize with other activities. For instance, one may find that one enjoys having music on while one reads. Aristotle does not address this worry, but it does seem that there is at least one plausible story for him to tell in response. If I think about why listening to music increases my enjoyment of reading, it seems that it is because it creates more suitable background conditions for reading. It is easier for me to split my attention between certain pieces of music (generally less dynamic ones) and reading than it is to read while coping with the more chaotic ambient sounds that the music drowns out. Also, the music may relax me and help me stop thinking about all the things I need to do the next day and thereby enable me to attend to my reading with greater focus. One of the conditions that must be in place for an activity to be pleasant is that the capacity being activated must be in a good condition. In this case, listening to music actually improves the condition of my capacity for reading by drowning out ambient sounds and relaxing me and thus removing various conditions that would otherwise impede my capacity for reading. Aristotle could say, then, that the synergy between the two activities exists not because the pleasure of listening to music increases the activity of reading, but rather because the activity of listening to music creates conditions that are conducive to the good performance of the activity of reading. If I were to enjoy the music too much it would presumably destroy my activity of reading because I would shift my focus away from reading. It seems, then, that this particular phenomenon is not a counterexample to Aristotle's view. Other phenomena need to be accounted for, however. 
A connected concern is that it is not clear how Aristotle can explain the pleasure of complex activities like watching a play. Watching a play involves (at least) activities of seeing, hearing, and thinking. If he were really committed to the strong claim that the pleasure of one activity always destroys other activities that are different in kind, it would be very difficult for him to explain the phenomena surrounding complex activities that involve the activation of more than one capacity for thought or perception. For his theory to be at all plausible, he must allow for complex activities to constitute a single, unified activity. After all, one of the activities he uses as an example in this very passage is watching a play, which is clearly a complex activity. If he allows for complex activities to count as a single activity, then the claim he is making is considerably weaker than it may seem and it becomes possible to make sense of various apparent cases of synergy between pleasant activities as cases where the subject in fact undertakes a single complex activity.

\section{Section 5: Is the Covariance Thesis compatible with the possibility of comparing pleasures with respect to pleasantness?}

Finally, I will consider the ramifications of Aristotle's acceptance of the Covariance Thesis for the question of how it is possible to compare pleasures in pleasantness. For Aristotle's theory to be plausible, it must be possible to compare pleasures that differ in kind in pleasantness. We frequently make decisions about how to act on the basis of such comparisons. For instance, I might pass on a concert in order to spend the evening reading a novel for the sole reason that I expect to enjoy the novel more than I would the concert. Or I might eat a peanut butter sandwich instead of going out for a more expensive lunch because I think I would reap more enjoyment overall if I saved my money to go to the movies the next day. Considerations 
beyond pleasantness often come into play in such decisions, but it would be prohibitively counterintuitive to deny that legitimate comparisons of pleasantness can play a role in these decisions.

On the other hand, it seems wrong to allow that pleasures can always be compared on a quantitative basis, as Bentham's influential theory of the hedonic calculus suggests. Bentham thinks that pleasantness can be quantified in terms of intensity and duration and that we can use this quantity to make comparisons in pleasantness. This would have counter-intuitive consequences if it were true. Suppose (assuming Bentham's theory) I enjoy eating a hot dog about a third as much as I enjoy attending a ballet. If someone offers to trade me four hot dogs for my ballet ticket and my goal is to have as pleasant an evening as possible then I should take the deal (assuming I have room in my stomach for four hot dogs). But this seems bizarre. Regardless of how many hot dogs I will get to eat and how much I will enjoy each of them, I may simply prefer the pleasure of the ballet over the pleasure of eating any number of hot dogs (even bracketing considerations such as the diminishing returns of eating so many hot dogs). This need not be because there are reasons aside from pleasantness for preferring the ballet; I might prefer the one kind of pleasure over the other for purely hedonic reasons. I might not be after the largest quantity of pleasure, but rather the highest quality pleasure.

Aristotle's theory seems to me to successfully find the middle ground between, on the one hand, denying that pleasures can be compared in pleasantness, and, on the other hand, making comparisons between pleasures a purely quantitative matter. He clearly commits himself to the possibility of comparing pleasures in pleasantness: 
Hence for each capacity the best activity is the activity of the subject in the best condition in relation to the best object of the capacity. This activity will be the most perfect and the most pleasant. For every perceptual capacity and every sort of thought and study has its pleasure; the most pleasant activity is the most perfect; and the most perfect is the activity of the subject in good condition in relation to the most excellent object of the capacity. (NE 1174b18-20)

In this passage, Aristotle states what it is for an activity to be the most perfect of its kind (i.e., the most perfect way of exercising the relevant capacity), and then states without further explanation or argument that such an activity will also be the most pleasant of its kind. His view appears to be that an activity's degree of pleasantness consists in its degree of perfection. This interpretation renders the inference in question unproblematic, and moreover makes very good sense if Aristotle identifies pleasure with the perfection of a perfect activity. But how can Aristotle maintain a ranking of pleasures in terms of degree of perfection without the notion of degree of perfection ultimately collapsing into a Benthamite notion of quantity?

I take it that the answer to this question can be found by tracing the influence of Plato's Philebus. Plato has Socrates state a general account of purity that grounds his understanding of the way pleasures can be compared in pleasantness, using whiteness as an example:

Socrates: Let us take whiteness first, if you have no objection. Protarchus: That is fine with me.

Socrates: Now, how can there be purity in the case of whiteness, and what sort of thing is it? Is it the greatest quantity or amount, or is it rather the complete lack of any admixture, that is, where there is not the slightest part of any other kind contained in this color?

Protarchus: It will obviously be the perfectly unadulterated color. Socrates: Right. But shall we not also agree that this is the truest and most beautiful of all instances of white, rather than what is greatest in quantity or amount?

Protarchus: Certainly.

Socrates: So we are perfectly justified if we say that a small portion of pure white is to be regarded as whiter than a larger quantity of an impure whiteness, and at the same time more beautiful and possessed of more truth?

Protarchus: Perfectly justified. 
Socrates: Well, now, we don't need to run through many more examples to justify our account of pleasure, too, every small and insignificant pleasure that is unadulterated by pain will turn out to be pleasanter, truer, and more beautiful than a greater quantity and amount of the impure kind. $(53 \mathrm{a}-\mathrm{c})^{14}$

'Pure' is used here to mean lack of admixture. Socrates says in this passage that pure pleasures are ones that are not mixed with any pain. I do not think that Aristotle takes up this view of what it is for a pleasure to be pure, since he does not accept the theory of pleasure that underlies it, but this passage from the Philebus is nevertheless very helpful.

I suggest that when Aristotle makes comparisons between pleasures, he is invoking a notion related to Plato's notion of 'purity'. Just as the whitest white is the purest white, and not the largest quantity of white, the most pleasant pleasure is the purest one, and not the one that maximizes some quantity. Aristotle explicitly links degree pleasantness with degree of purity in NE 10.7:

Besides, we think pleasure must be mixed into happiness; and it is agreed that the activity in accord with wisdom is the most pleasant of the activities in accord with

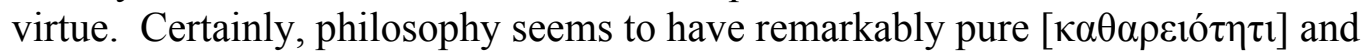
firm pleasures, and it is reasonable for those who have knowledge to spend their lives more pleasantly than those who seek it. (NE 1177a22-27)

I propose that Aristotle's notion of purity tracks degree of perfection—lack of admixture with imperfection. An important piece of evidence for this idea is found in NE 10.5:

Sight differs from touch in purity, as hearing and smell do from taste; hence the pleasures also differ in the same way. So also do the pleasures of thought differ from these [pleasures of sense]; and both sorts have different kinds within them. (NE 1175b36-a3)

${ }^{14}$ Translated by Dorothea Frede, in Cooper, John M. (ed.) and Hutchinson, D.S. (ed.), Plato: Complete Works. [Indianapolis: Hacket, 1997]. 
Peter Hadreas has persuasively argued that this ranking of capacities in purity depends on the extent to which each capacity is capable of apprehending order. ${ }^{15}$ As I discussed in section 1 above, a capacity in a better condition is thereby more capacious and so requires a more demanding object to be fully activated. We can make the same sort of comparison between different faculties as we can between more and less perfect ways of activating the same faculty. Thought apprehends order to a greater extent than sight, which apprehends order to a greater extent than smell, which apprehends order to a greater extent than touch, and so on. A perfect activity of a purer capacity (i.e., one that apprehends order to a greater extent) is more pleasant than a perfect activity of a less pure one, because the purer capacity is more capacious in the same basic way that a capacity in better condition is more capacious than the same capacity in a worse condition. If perfecting an activity is a matter of fully utilizing the relevant capacity so as to fully realize its nature, then a capacity that is more capable of apprehending order has more room for perfection than a capacity that is less capable of apprehending order. ${ }^{16}$ Fully utilizing a purer capacity is more demanding than fully utilizing a less pure capacity. All it might take to perfect an activity of touch is a smooth surface (which requires a minimal amount of order),

\footnotetext{
${ }^{15}$ Peter Hadreas, "The Functions of Pleasure in NE X 4-5," Ancient Philosophy 24 (2004): 15567.

${ }^{16}$ Francisco Gonzalez, in “Aristotle on Pleasure and Perfection.” Phronesis 36 (1991): 141-159. has made the interesting suggestion that Aristotle's ranking of capacities in purity is based on the extent to which a given capacity can assimilate to its object. I take this suggestion to be a promising way to explain more precisely why the extent to which an activity involves an apprehension of order is directly proportionate to its degree of perfection. Because touch cannot assimilate to its object as fully as thought, the capacity cannot be as fully utilized by a given activity. There will always be indefiniteness and fluctuation, and the possibility of an even more intense pleasure. I suspect there is a fruitful connection between this idea and Plato's classification of certain pleasures in the Philebus as belonging to the class of the "unlimited," but exploring this connection is outside the scope of this piece.
} 
while an activity of sight may require a beautiful landscape (which requires much more order) and an activity of thought may require a literary masterwork (which requires a tremendous amount of order).

Aristotle can say, then, that comparisons in pleasantness should be made in terms of which of two pleasures has the highest degree of perfection, and that this has nothing to do with Benthamite quantification. Any amount of experiencing a pleasure of touch, no matter how vast, would be less pleasant than even a few minutes of virtuous theoretical study. To say that the one is more pleasant than the other is to say that one is more perfect than the other. Duration and intensity are irrelevant to comparisons in pleasantness, except insofar as they are integral to a given activity's perfection (e.g., a certain duration would be required for a perfect activity of listening to a certain piece of music). This aspect of Aristotle's theory seems to me to be extremely attractive and intuitive. When we choose one activity over another simply because we expect it to last longer, we are choosing on the basis of a practical consideration about how best to utilize our available time rather than on the basis of pleasantness. Determinations about pleasantness depend on the intrinsic character of the activities themselves.

\section{Conclusion}

My aim in this paper has been to give an interpretation of Aristotle's series of arguments for the Covariance Thesis, and in so doing to explore the significance of the thesis and of these arguments. I have made the case that, for Aristotle, pleasure is as phenomenally heterogeneous as mental activity is, but that he does think that the phenomenal character of any pleasant activity will have a certain structure. Namely, he thinks that ceteris paribus when one takes pleasure in performing an activity, one will perform the activity with progressively greater aptitude, focus, 
enthusiasm, and so on. This is due, I have argued, to the manner in which a perfect activity improves the conditions for its own performance. I have also considered the prospects for comparing heterogeneous pleasures in pleasantness, and argued that Aristotle's theory has the resources to allow for an intuitively attractive account of how such comparison is possible.

\section{University of Montana}

\section{Bibliography}

Anscombe, G.E.M., "Modern Moral Philosophy," in The Collected Philosophical Papers of G.E.M. Anscombe, vol. 3, Ethics, Religion, and Politics. [Oxford: Basil Blackwell; Minneapolis: University of Minnesota Press, 1981]: 27.

Bostock, David, "Pleasure and Activity in Aristotle's Ethics," Phronesis 32 (1988): 251.

Gonzalez, Francisco, “Aristotle on Pleasure and Perfection.” Phronesis 36 (1991): 141-159.

Hadreas, Peter, “The Functions of Pleasure in NE X 4-5,” Ancient Philosophy 24 (2004): 155-67.

Hardie, W.F.R, Aristotle's Ethical Theory [Oxford: Oxford University Press, 1980]: 314.

Aristotle, Nicomachean Ethics. Trans. and commentary by T.H. Irwin [Indianapolis: Hackett, 1999].

Plato, Plato: Complete Works. Ed. John M. Cooper and D.S. Hutchinson [Indianapolis: Hackett, 1997].

Strohl, Matthew, "Pleasure as Perfection: Nicomachean Ethics X.4-5," Oxford Studies in Ancient Philosophy 41 (2011): 257-287.

Taylor, C.C.W., "Pleasure: Aristotle's Response to Plato," in Plato and Aristotle's Ethics, ed. R. Heinaman [Aldershot: Ashgate, 2003]: 19-20.

Van Riel, Gerd, Pleasure and the Good Life. [Leiden: Brill, 2000]: 77. 